\title{
Itapororócas: termo Tupi, marco Tapuia
}

\author{
Itapororocas: term Tupi, landmark Tapuia
}

\author{
Jaime Magalhães Morais** \\ Universidade do Sudoeste da Babia \\ Vitória da Conquista, Bahia, Brasil \\ João Batista de Castro Júnior ${ }^{* * *}$ \\ Universidade do Estado da Babia \\ Brumado, Estado da Bahia, Brasil
}

\begin{abstract}
Resumo: Itapororócas é uma palavra de origem Tupi, que dá nome a uma das freguesias estabelecidas em finais do século XVII, no Estado da Bahia. Contudo a denominação provavelmente já era usada no segundo quartel do século XVI e, a partir de inícios do século XVII, já se encontram documentos citando a serra com este nome, indicando sesmarias adquiridas mediante doação, documentos de propriedades e registros de compra e venda cuja tradução para a língua portuguesa gera o termo, registrando um fato de suma importância no resgate da fala dos povos nativos Paiaiá no Brasil, e as expedições feitas pelos portugueses na conquista do sertão.
\end{abstract}

Palavras-chave:: Expedições. Catequese. Tapuias. Memórias.

Abstract: Itapororocas is a word of Tupi origin which gives its name to one of the parishes established in the late seventeenth century in the state of Bahia. However the name was probably already used in the second quarter of the sixteenth century and, from the beginning of the seventeenth century are already documents citing saw with this name, indicating allotments acquired by donation, property documents and purchasing records whose translation to Portuguese generates a term, registering a fact of great importance in the rescue of speech of native peoples Paiaia in Brazil, and the expeditions made by the Portuguese in the conquest of the hinterland.

Keywords: Expeditions. Catechesis. Tapuias. Memory.

\section{INTRODUÇÃO}

Esta análise tenta dar conta do termo "Itapororócas" e seu significado linguístico e histórico. Tal estudo se justifica em função de Serra das Itapororócas já ser conhecida por esse nome em inícios do século XVII em documentos oficiais.

Servimo-nos como referencial teórico da obra, Fidalgos e Vaqueiros de Eurico Alves Boaventura e Seis Séculos de Artilharia, do Tenente Coronel J. V. Portella F. Alves. Enquanto o primeiro analisa o sertão baiano e, entre outros muitos temas, o termo

\footnotetext{
** Professor da Rede Pública do Estado da Bahia, licenciado em História, Mestre em Memórias: Linguagem e Sociedade pela UESB. E-mail: jagamor@gmail.com

*** Professor da Universidade do Estado da Bahia, Campus XX, Brumado. Mestre e Doutor em Linguística Histórica pela Universidade Federal da Bahia, Salvador, Bahia.
} 
Itapororócas, o segundo registra a evolução do manancial bélico ao longo dos séculos. A metodologia empregada obedece aos princípios estabelecidos pelo Método compreensivo-interpretativo, ao qual se refere Marilena Chaú, na obra Convite à Filosofia.

Os jesuítas usavam para a catequese, desde que chegaram ao Brasil, uma doutrina pedagógica voltada para a memorização dos conteúdos ministrados pelas diversas disciplinas que compunham o currículo, dentro das escolas, conforme Ana Palmira Bittencurt Santos Cassimiro no artigo, Cartilhas e catecismos usados no Brasil Colonial (2005, p. 182-205). Nos primeiros contatos que tiveram com os nativos, perceberam a ênfase cultural que essas comunidades devotavam à memória dos ancestrais e seus feitos, pela oralidade. Efetivamente havia um grande número de povos pagãos que, segundo os propósitos daqueles missionários, careciam de uma doutrina diferenciada em relação ao que se praticava na Europa, onde o Renascimento e o movimento de Reforma Religiosa pregavam o fim do analfabetismo, admitindo haver necessidade de a Igreja se aproximar das camadas populares, tendo credibilidade em alta nos países ibéricos, após as vitórias sobre o Islamismo.

Aqueles primeiros anos do estabelecimento dos jesuítas foram também os das primeiras expedições portuguesas com as entradas e bandeiras baianas para alargamento das capitanias em direção à Linha de Tordesilhas, adentrando parte dos sertões. Muitos não tiveram o êxito esperado, devido substancialmente à falta de quem se aventurasse a estabelecer residência próxima aos domínios Tapuias, correndo o risco destes voltarem com maior efetivo e destruir as construções, por estarem estas isoladas do litoral onde as forças e munições das tropas portuguesas se concentravam. Tal situação permitia aos jesuítas ter tempo para se dedicar com mais afinco às suas tarefas e conquistar a confiança de muitos grupos de nativos de diferentes troncos linguísticos, tanto no litoral como em aldeias mais afastadas.

É de importância significativa, observar que as aldeias nativas ficavam nesse período dentro do antigo domínio Tupi ou próximo aos seus limites, até quando Portugal fez a Restauração da Coroa na luta aos castelhanos e assim pôde agir com maior energia aos constantes ataques Tapuias ao litoral na tentativa de retomar seus territórios perdidos pelas investidas dos nativos Tupis num período precedente à colonização, segundo Gabriel Soares de Souza na obra Tratado Descritivo do Brasil em 1587 (1851, p. 338). Não foram sem resultados os esforços dos jesuítas, que, já em finais do século XVI, tinham constituído aldeias tanto no litoral mais distante de Salvador, como fora do perímetro urbano da Capital da colônia

Alguma delas evoluiram de modo a mais tarde serem transformadas em vilas, a exemplo de aldeia do Espírito Santo, hoje bairro de Abrantes; Conde, atual São Francisco do Conde e Cachoeira; cuja extensão do território, se estendia do rio Paraguaçu até o rio Itapicuru. Cachoeira, mais tarde se tornou ponto de penetração dos jesuítas nos sertões, seguindo o rumo das estradas boiadeiras.

Nos idos da União Ibérica, novas expedições foram feitas contra os Tapuias, que após a retirada dos expedicionários, voltavam as suas antigas posições. Desde os primeiros contatos havidos, todavia, com os jesuítas, esses últimos se utilizaram de alguns hábitos 
nativos para fazerem-se próximos da cultura, a exemplo das construções dos templos que inicialmente eram feitos de casas de taipa, até na Capital, de acordo com Luis Alves de Mattos na obra Primórdios da Educação no Brasil (1958, p. 53). Certamente por estas serem menos afeitas aos incêndios que as construções Tupis que cobriam a abóboda formada por suas habitações com palhas de palmeiras, porém diferenciando-se destas pela conformação das paredes com barro, tendo a planta forma retangular, se bem as primeiras também usassem palmas no teto.

\section{A CATEQUESE E SUAS CONSEQUÊNCIAS}

Guedes de Brito, aproveitando as benesses do Governador Tomé de Souza, de quem recebeu seguidas concessões de sesmarias em função de ter organizado bandeiras de combate nos sertões, foi dos primeiros a alargar os horizontes da catequese aos Paiaiá. Vasco Rodrigues de Caldas, também fez investida ao sertão entre 1558 e 1561, devidamente catalogadas na pesquisa de Luis Henrique Dias Tavares, que leva o título História da Bahia (2001, p. 157). Já no Governo de Duarte da Costa, os Tapuias ou Jês, sentindo a fragilidade das posições dos Tupis submetidos pelos portugueses, tentaram se apossar de áreas litorâneas, obrigando o Reino a reagir na perseguição que acabou gerando a Capitania do Paraguaçu, tendo como primeiro donatário o filho do Governador, Álvaro da Costa. Deve-se alertar para o fato de que, mesmo em nossos dias, populações que habitam áreas próximas ao litoral, no sertão, se deslocam para a pesca da pititinga no oceano.

Não seria nada incomum que naquele período que as refregas entre Tapuias e Tupis fossem corriqueiras em determinado período, devido à tradição da pesca da pititinga obedecer a um ciclo pelo qual os animais aquáticos adentravam a foz dos rios no período da piracema para desova. Ambos os grupos se enfrentarariam, no momento que as espécies, emigrassem.

A pititinga era importante para a confecção da farinha de guerra dos Tapuias (SOUZA, 1851, p. 178). Mas, não eram encontradas em todas as ocasiões do ano, nem ao longo dos rios em sua extensão maior, se restringindo apenas as imediações da foz.

Daí, haver uma época propícia a sua pesca, que normalmente se dava quando os rios ficavam mais caudalosos, o que se faz em períodos de trovoadas mais intensas no sertão e permite situarmos, nos meses de novembro a janeiro. Estes meses concentram no verão nordestino, as maiores enchentes que se tem notícias.

Quando se avizinhava o final do século XVI, outras expedições, a exemplo da comandada por Gabriel Soares em 1591 em busca das minas de prata de Bélchior Dias Moreia - que acabou por lhe custar a vida ao contrair uma moléstia onde escasseava o conhecimento dos recursos medicinais -, exploraram parte dos domínios Paiaiá até a nascente do Rio Paraguaçu (TAVARES, 2001, p. 159). Essas expedições normalmente tinham sacerdotes que se estabeleciam entre os nativos.

Muito embora os expedicionários retornassem ao litoral com os despojos de guerra que incluíam os prisioneiros ao efetivo de escravos, não ocorria o mesmo aos religiosos, que se misturavam aos mais promissores fiéis para que a prática religiosa frutificasse, 
passando a exercer liderança sobre esses povos a partir da educação que ministravam. Por esse tempo, já entendiam os termos usados por cada tronco linguístico, o que lhes permitiu avançar na grafia e ensinar-lhes a codificação alfabética na vocalização tradicional de cada língua. No litoral, evoluíram na língua Tupinambá, de tal forma a construírem dicionários e gramáticas para conhecimento dos seminaristas e egressos do Continente Europeu desde o início da evangelização, conforme Mattos (1958, Cap. III). Se serviam dos curumins, que lhes ensinarem a correta vocalização das palavras da língua vernácula e depois grafavam de acordo com os princípios que regiam a gramática portuguesa.

Assim, nomes e tradições outras foram incorporadas aos rituais cristãos como forma de se fazerem melhor entendidos. Acidentes geográficos, aldeias, rios, bem como o relevo, hábitos e expressões culturais, ganharam importância significativa a exemplo dos múltiplos empregos de termos, ainda hoje encontradas no Brasil e já usadas naquele período. A título de ilustração, pode-se citar os cultivos que permitiram a dinamização da culinária, com novas e desconhecidas receitas, a extração de frutos nativos, o conhecimento dos diversos tipos de insetos domésticos e sua produção listados na obra de Victor Renault, Thesouro das Famílias: ou dos conhecimentos úteis, enciclopédia da vida prática (1910, p. 688-689). A Língua Tupi, abraçou inclusive os portugueses litorâneos e mais tarde os Tapuias, que eram catequisados pelos jesuítas.

\section{A DESIGNAÇÃO}

A esses pioneiros no estudo cultural do sertão baiano, agregaram-se aqueles catequizados com maior conhecimento topográfico e espírito de aventura que indicavam as veredas, tratavam as enfermidades com os recursos naturais e localizavam os perigos, uma vez que estavam acostumados ao cheiro, ao barulho, ao trato com a natureza e alertavam para as suas especificidades (MATTOS, 1958, p. 67-68). Assim foi em relação à elevação chamada Itapororócas, termo nativo para o que hoje é conhecida por Serra de São José, localizada no atual Distrito de Maria Quitéria, dentro do Município de Feira de Santana.

É importante que alertemos para o relevo pouco acidentado, que separa as áreas continentais do Recôncavo, do espaço intermediário para os sertões baianos, onde predominam faixas que se estendem de norte a sul e acompanham geograficamente o desenho da costa, ora se espraiando até ela, ou distanciando-se ao semiárido por vários quilômetros. Isto se justifica, em razão dos portugueses carecerem dos acidentes naturais como as elevações, para posicionar suas armas de fogo mais potentes.

Conforme Boaventura (1989, p. 389, apud SAMPAIO, 1958, p. 54), Itapororócas significa, "pedras que caem fazendo barulho". Ita: pedra. Pororóca: barulho. Essa interpretação traz certo incômodo, não só ao habitante do tabuleiro, porque não se entende pedras cairem sem que ocorra um fenômeno natural, climático ou artificial, que dê início ao processo, o que deixa um hiato no ar, muito embora a serra de São José, se situe no seu limite noroeste.

No tabuleiro há escassez de elevações, o que de imediato afastaria a hipótese de seixos rolarem de uma montanha. Portanto, se faz necessário esclarecer, a qual tipo de 
ocorrência, se deve esse acidente, que além disso, carece também se dar luz a qual tipo de pedras, a tradução se está referindo, ou melhor, se os nativos designavam com esse termo, a todo tipo de pedras.

Mas devido a um dos maiores estudiosos do povoamento de Feira de Santana, Renato de Andrade Galvão ter localizado documentos com citação da Serra das Itapororócas, que datam de 1615 é possível aproximarmos os fatos, que foram publicados no artigo Os povoadores da região de Feira de Santana (1982, p. 25). Com o nome de São José das Itapororócas ficou conhecida a capela que teve em João Peixoto Viegas seu restaurador a partir de 1640, período em que se estabeleceu na área e foi atacado pelos Tapuias Paiaiá. $\mathrm{Na}$ ocasião a fazenda com o templo foi destruída por um incêndio, conforme declaração que prestou ao Tribunal da Inquisição estabelecido em 1646, quando foi denunciado à instituição, cujos inquisidores faziam parte da Companhia de Jesus.

Chamamos a atenção para a proximidade desse fato, com a Guerra da Restauração Portuguesa, na qual o nobre João de Bragança foi elevado ao trono sob o título de D. João IV. João Peixoto Viegas havia comprado de João Lobo de Mesquita parte de uma concessão em favor de Miguel Ferreira Feio em 1615 e a ela agregou outra concessão da sesmaria do Tocós em 1619.

Só em 1655 teve reconhecida a propriedade, já pelo novo rei português. A partir daí se intensificaram os combates contra as bases Tapuias, estendendo-se até finais do século, quando São José das Itapororócas passou à freguesia dentro da Comarca de Cachoeira (GALVÃO, 1982, 26). Até então, era área de catequese dos jesuítas.

Como atrás já alertamos, os jesuítas ensinavam a Língua Tupi, a todos os nativos catequizados, com o objetivo de unificar o idioma. Mas, a concessão da sesmaria a João Peixoto Viegas, se tornaria um estorvo por conta da área ser passagem das boiadas, que eram tangidas pelos vaqueiros dos sertões, para o litoral.

Durante sua vida - que se estendeu aproximadamente ao último quartel do século XVII - João Peixoto Viegas foi administrador dos Paiaiás e legou o morgado à sua descendência, tendo um homônimo (seu neto) assumido a tal administração até sua morte no segundo quartel do século XVIII, conforme a dissertação de Celeste Maria Pacheco de Andrade que leva o título de Origens do povoamento de Feira de Santana: um estudo de História colonial (1990, p. 99). Com isso, entende-se que houve tentativas de conter a ação do sesmeiro mais velho, mas, este usando da perspicácia, safou-se das acusações e, contando posteriormente com o apoio da Coroa, pôde finalmente vencer a resistência dos nativos que ficariam sob sua tutela em reconhecimento pelo serviço prestado, na área averbada a colônia.

Ainda sobre a capela de São José das Itapororócas, notamos uma mescla das culturas priorizando as crenças católicas, mas não necessariamente ignorando os termos encontrados dentro da cultura nativa. Isto, se por um lado, favorecia os da terra porque documentava nomes consagrados dentro do grupo e não destruía a memória, por outro, mesmo os militares portugueses se aproveitavam do desconhecimento cultural dos autóctones em relação às suas técnicas, para com suas armas e táticas de guerra lhes impor sua supremacia. 


\subsection{TÉCNICAS E TÁTICAS DE GUERRA}

Se valiam das elevações acidentadas para posicionar armas de fogo de longo alcance nas encostas e assim poderem melhor visualizar os inimigos precavendo-se com o segredo, que envolve as operações da caserna, de acordo com João Capistrano de Abreu, na obra Capítulos da História Colonial (1976, p. 100). Era esse um hábito dos milicianos paulistas, nos combates que se estabeleceram contra os nativos, a partir do século XVII.

As montanhas facilitavam a visualização, ao mesmo tempo em que se colocavam a salvo das flechas pelos nativos atiradas, se escondendo na vegetação. A distância do sopé ao cimo é mais um fator a ser considerado, para que as elevações se desse preferência.

Àquela época, o municiamento das armas de fogo mais potentes como os canhões era feito com pólvora preta e as balas usadas no disparo tinham por prioridade aquelas pedras que se encontravam na natureza e tinham a forma esférica, como podemos deduzir a partir das fotografias expositivas tanto das praças das algumas cidades brasileiras, como até na zona rural, a exemplo das localizadas no Rio do Peixe, conforme artigo de autoria de Jaime Magalhães Morais de título, Origens do Tabaréu (2012, p. 5). Necessariamente assim se fazia porque além de não desgastar as tropas no deslocamento com uma carga de peso considerável como as balas de ferro, evitava-se o sobrepeso pela necessidade de transportar as peças, que nem sempre eram desmontáveis, dificultando o transporte.

Até porque, no leito dos rios que cortam o tabuleiro, se colhia a água necessária ao abastecimento das tropas, que tanto era composta de animais de carga, como dos soldados. $\mathrm{Na}$ escalada das elevações, se dá um esforço físico considerável, que tem necessidade da reposição líquida nessas espécies.

O transporte era feito preferencialmente em lombos de jumento ou burros (ALVES, 1959, p. 234-235). Os primeiros canhões ainda estavam em fase de evolução no Continente Europeu, onde eram construídos, de tal forma a haver grande possibilidade dos acidentes, comuns aos soldados operadores desse apetrecho.

As balas de pedra, também chamadas pelouros, eram mais leves que as de ferro e poderiam alcançar um alvo mais distante embora nem sempre causasse os mesmos danos que as de ferro. Mas, considerando que a rigidez das pedras é maior e a liga do ferro não permite que um impacto resulte em esfacelamento do projétil, as de pedra poderiam até atingir uma área mais vasta se encontrasse na trajetória alguma força estática mais resistente, provocando, por conseguinte maiores prejuízos com os estilhaços a se multiplicar.

As peças de canhões, como a roqueira, o morteiro e a bombarda, eram mais específicas para o disparo, utilizando-se dos pelouros, e em geral os canhões tiveram uma evolução muito lenta durante todo o período colonial, de acordo com o artigo de Ricardo Bonalume Neto, de nome Chuva de Aço (2010, p. 6). Considerando que, no leito dos rios se acham pedras desgastadas, com forma arredondada, em números bem maiores que no resto da natureza, certamente eram colhidas para uso como projéteis.

Os primeiros pelouros produzidos no continente europeu, se utilizavam das pedras, que usinadas para tomar a forma esférica, se constituiriam nos projéteis, mas ainda assim, era uma carga demais densa, para o transporte e dificultava a subida dos animais num 
terreno em aclive. Melhor seria que se adaptasse o que fosse encontrado mais facilmente, próximo ao acampamento das tropas.

As experiências não progrediram muito com os canhões, fundamentalmente porque foi a Igreja quem primeiro as fez, e não tinha interesse em armar os países vizinhos, podendo, depois disso, ter que encará-los como adversários, a exemplo dos Países Baixos e Ingleses, sem contar com a fragmentação do Sacro Império com as revoltas internas e criação de novos reinos. A catapulta, ou melhor, o onagro era arma bastante utilizada no Mundo Antigo, usada na impulsão de balas de pedra e aperfeiçoada pelo Império Romano durante sua expansão, segundo a obra de Rubim Santos Leão de Aquino que leva o título, História das Sociedades: das comunidades primitivas às sociedades medievais (1980, p. 233). Constituía-se em um engenho móvel com alavancas feitas de vigas de madeira enlaçadas por cordas ao tensor que, mediante torque dos soldados e a descompressão repentina, alçava enormes pedras em fortificações de cidades adversárias.

Portanto, já existiam experiências anteriores a estas, no uso desse recurso nos combates, dos quais a Igreja tinha ciência por conviver largo período entre a elite, dentro desse Império. Melhorias no poder destrutivo das armas se concentraram na escolha do material apropriado para as peças utilizadas nos combates, adaptadas ao uso da pólvora como propulsora dos projéteis, novidade do fim da Idade Média.

Ora usavam o ferro que precisava de uma liga mais flácida, ora o bronze, material menos ríspido, cuja liga plástica resistia melhor aos disparos (ALVES, 1959, p. 80). Mas, se o bronze permitia menor risco de acidentes aos soldados e das peças ao impacto dos tiros, o ferro não causava deformações nas câmaras e tinha maior durabilidade pela rigidez do metal.

Os soldados ficavam expostos ao recuo da explosão, caso o cano da arma se rachasse na culatra, o que ainda era comum. Contudo, o bronze, apesar de ser uma liga flácida, que suportava melhor aos impactos, também precisava de manutenção constante, o que encarecia seu uso pelas tropas e tirava a arma dos campos de batalha, carecendo de substituição por novo, ou retificado equipamento.

O ferro, por sua vez, provocava outros percalços, porque se oxidava com maior rapidez, carecendo de manutenção constante com lubrificantes (ALVES, 1959, p. 97). O lubrificante mais comum ao período, se constituia do sebo, proveniente dos mamíferos, tipo carneiros e o gado bovino, que o pequeno território português, distribuido com outros cultivos, não cedia espaços mais amplos, compreendendo restritas áreas das pastagens, que não davam conta de produzir de forma a suprir o mercado interno.

Nos outros países com quem Portugal mantinha relações e poderiam comercializar para conseguir as matérias primas necessárias para levar adiante as experiências, também se desenvolviam pesquisas e seguramente não estavam dispostos a fornecê-las. De modo, que sobrava a alternativa, de produzir nas suas colônias, o que tivesse carências, daí se inserir no Brasil, a produção do gado bovino, já no início da colonização.

A forma do municiamento também passava por processo evolutivo, no qual armas poderiam ser carregadas ou pela boca ou pela culatra (ALVES, 1959, p. 97). E os especialistas do período (religiosos) deveriam estar atentos às experiências feitas com uma peça inteira do canhão, em relação àquelas com partes separadas a serem montadas. Isto 
leva a crer não ter havido grandes diferenças no tempo útil entre as peças feitas de bronze ou de ferro, porque ambas eram usadas nos combates.

Porém, as armas que vieram a compor o arsenal brasileiro daquela época - em se tratando de colônia portuguesa - provavelmente não foram as de melhor qualidade, devido às guerras que concomitantemente aconteciam na Europa demandarem maior cuidado, em função de se temer a invasão do território metropolitano pelas forças inimigas. Há maior zelo militar onde normalmente se concentra a cúpula do poder. Além disso, a limitação bélica do nativo que usava armas obsoletas em relação às técnicas e estratégias europeias exigia menores custos com munição que as novas tecnologias fomentadas na Europa, de forma que os pelouros como projéteis, e os canhões como armas de fogo, entre outras de menor calibre e poder de destruição, certamente foram as mais usadas na anexação do sertão às áreas coloniais portuguesas, até porque projéteis como os pelouros poderiam ser confundidos com seixos encontrados na natureza e, assim, deixar poucas evidências da luta, salvo para os que presenciavam o fato. Vale lembrar que desde o homem primitivo as pedras eram usadas como forma de defesa e ataque, um dado considerável ainda presente, que os estudiosos não deveriam ignorar.

Convém salientar que os nativos não conheciam a técnica de fusão do ferro, de maneira que empregavam na língua Tupi, o mesmo termo para o metal que os seixos: ita, conforme observa Couto de Magalhães, na obra O Selvagem (1876, p. 31-35). Certamente as balas de metal também levavam a mesma designação que os pelouros, ou os seixos.

Do forma que, outros objetos fundidos de metal levavam o mesmo prefixo na Língua Tupi, que se disseminou também pelos sertões, onde os jesuítas faziam a catequese. A colonização, ou a missão de pregar aos pagãos, se deveria iniciar com uma língua geral, para depois dar sequência, com a educação religiosa e normas de conduta que garantissem o domínio da metrópole sobre os súditos do reino.

Embora com o posterior contato com as etnias onde esse conhecimento já fosse fomentado, oportunizasse a aprendizagem da forma de manuseio, pelo que se pode deduzir no relato do assassinato de Manoel Barbosa de Mesquita em 1670 na aldeia de Cairu, quando se utilizou de duas pistolas para tentar conter os nativos revoltados, segundo Sebastião da Rocha Pita, na obra História da América Portuguesa (1730, p. 382). Além dessa arma de pequeno calibre, outras como a garrucha, o mosquete, o clavinote e a espingarda já deveriam ser bem difundidas a julgar pela necessidade de defesa nos engenhos. Já os negros artífices, empregados na confecção de armamentos, numa posterior fuga para áreas autóctones criavam relações de troca das técnicas e produtos.

Entendendo que os portugueses trataram de melhor defender as costas brasileiras contra os invasores europeus por recearem estes invadir o território com armas até certo ponto equiparáveis ao seu arsenal, numa área que teoricamente detinham a posse, muito embora suas naves não encontrassem semelhante mobilidade até então, em razão do rápido deslocamento e estrutura capaz de abrigar maior potencial bélico, reproduziam consequentemente às táticas da metrópole. Ou seja, as investidas contra os Tapuias eram feitas com armamento de poder de fogo menor, enquanto as estratégias de guerra se utilizavam de táticas adequadas às armas de fogo da época, como o estabelecimento na 
crista das montanhas, o uso da bússola e da luneta, considerando as limitações técnicas desses povos em relação aos europeus.

É de notar que, durante a invasão holandesa à Bahia, que encontrou no bispo D. Marcos Teixeira de Mendonça organizador da reação contra essa investida, às costas baianas serviram como verdadeiras paredes de um castelo natural contra as naus inimigas. Peças de canhão eram estabelecidas em diversos níveis tanto para confundir a localização aos adversários como para facilitar aos soldados apagar incêndios ocasionados pelas buchas que facilmente entravam em combustão a partir dos tiros, cujo municiamento era feito com pólvora preta, mais propensa aos acidentes (NETO, 2010, p. 6). A vegetação do semiárido, sendo mais afeita à combustão em razão das estiagens anuais a que se submetem ou mesmo pelas especificidades em sua conformação química, carecia de um cuidado redobrado de quem se disponibilizasse a atacar o nativo.

Essa tática se produziu também em relação a Serra das Itapororócas, enquanto as expedições se propusessem a fazer guerra aos Tapuias Paiaiás. O uso das pedras como projéteis não era estranho aos nativos que as utilizavam para municiar a funda, ou mesmo o badogue (bodoque) primitivo, arco adaptado com pedaços de couro numa corda dupla para a caça, a defesa ou para manter as aves daninhas distantes dos cultivos que, durante a fase mais tenra das plantas, ficam vulneráveis à predação. A linguagem empregada pelos povos que habitavam o Brasil é mais um dado a se considerar por conter certas características que se misturavam às suas crenças, em que o mito, o arquétipo e a lenda se confundiam, simplificando os termos que vinham carregados dos saberes históricos do grupo, nas memórias dos ancestrais reavivadas a cada aglomeração.

\section{EM BUSCA DE APORTE CONCLUSIVO}

Alie-se a isso, a estrutura da linguagem não obedecer aos critérios da língua portuguesa. Assim, os ataques sofridos pelos Paiaiás deveriam ser momentos aterradores, nos quais inimigos usavam pedras em número relevante para seus padrões e incomuns em termos de massa para arremesso, causando prejuízos de toda espécie, sendo precedidas do estampido da pólvora das armas que provocavam barulho. Como a detonação era semelhante ao trovão, um dos seus mitos, o temor prevalecia como sentimento do grupo pelo fenômeno natural causar pavor. A surpresa advinda sem sinais da natureza lhes serviu de marco, porque nas suas crenças até mesmo os raios deixavam como vestígio uma pedra onde caiam: As pedras de raio. E o substantivo "ITA", que precede "PORORÓCAS", certamente está relacionado à velocidade do som que não é compatível à do projétil, de forma que eram primeiro atingidos com as pedras e só depois o estampido se fazia audível. Assim, na Língua Tupi, ita, enquanto primeiro objeto visível, precede pororócas, que segue as pedras, com a detonação sendo ouvida e a núvem de fumaça a levantar-se, indicando de onde partiu.

Observe-se que o último lexema está no plural, a revelar a significação que mais de uma delas foram atiradas. Outra vertente permite visualizar, que o nome da serra indica ser este batismo, num período precedente a 1615 , quando os Paiaiás teriam sido atacados por tropas portuguesas do alto da serra e a partir desse momento, passou a ser identificada 
como Serra das Itapororócas pelo nativo. Devido às condições físicas da área, o sesmeiro João Peixoto Viegas preferiu este local ao tabuleiro, para seu estabelecimento, julgando garantir maior segurança junto ao monte, de onde se defenderia, ou atacaria os nativos.

Num passado nem tão distante e impreciso, o nativo ao tomar contato com os jesuítas, já passado o primeiro episódio e período das estiagens, avizinhando-se o plantio percebeu coincidir o dia 19 de março do calendário cristão (numa escolha providencial dos religiosos), com o dia do santo católico São José. Nessa data era quando todos se dedicavam às tarefas que envolviam mulheres e crianças, em razão das chuvas benfazejas para o início dos cultivos que alimentariam o grupo, associados aos primeiros contatos e devidamente acompanhados de guias Tupis, encontrando acolhida maior das suas pregações em razão da crença na boa sorte, na bênção dos céus, no sobrenatural. Dos contatos reiterados entre sacerdotes e fiéis sentiu-se a necessidade de um local apropriado para as orações e rituais, as quais o grupo, em regime de adjutório, se uniu em torno da construção para estabelecer a capela confeccinada de taipa e sua primeira missa, rezada em data comemorativa ao padroeiro.

Contudo, ao João Peixoto Viegas tomar posse da sesmaria, se dispôs a construir a sede, junto da capela, o que certamente desagradou o grupo de nativos, que a tinham construido e frequentavam o templo. Daí atearem fogo a casa e a capela, numa tentativa de se vingar, por terem lhes subtraído parte das suas posses. Com isso, os jesuítas, que desejavam eternizar memórias ligadas à fé, agregaram ao nome de capela de São José, um referencial mais localizado e de conhecimento da maioria: Itapororócas.

Esse termo Tupi se fez entender primeiro àqueles que faziam parte do grupo que falava a língua litorânea, mas as aulas ministradas pelos sacerdotes, até quando foram expulsos em 1759, regidas em Tupinambá ou nheengatu (fala boa), poderiam evocar lembranças e associações nos ancestrais mais antigos entre os Tapuias, ainda remanescentes e repassadas pela tradição à tribo (MAGALHÃES, 1876, p. 4). E o novo grupo formado dessa miscigenação, mais adiante submetido aos cuidados dos militares, legou ao esquecimento grande parte das tradições, perdendo inclusive o curso dos fatos que fariam a ponte entre o passado Tapuia, em que se incluíam os Paiaiás, e o presente Tabaréu, no tabuleiro. Mesmo assim, ainda deu pistas valorosas para se concluir, por tudo aqui exposto, que seguramente fica mais adequado ao português a tradução literal de "Itapororócas" para: Pedras atiradas com barulho.

Entretanto, partindo do princípio da carência na língua Tupinambá de uma palavra específica, pelo objeto ser até então desconhecido e pouco visualizado no grupo, certamente se utilizaram de um artifício linguístico justapondo dois substantivos para permanecer a inteligibilidade da idéia, ainda que desfocado na sua aparência concreta e sem precedentes na memória, criando consequentemente a partir daquela data um marco referencial divisório no tempo, pois, se os nativos chamavam ita tanto o seixo como o ferro - matéria prima com relativo uso, já transformado em peça de artilharia europeia pelas forjas e/ou usinagem - Itapororócas também se refere a própria máquina de onde partiam os disparos com as pedras. Ou seja: canhão.

\section{REFERÊNCIAS}


ABREU, Capistrano de. Capitulos de História Colonial (1500-1800). 6a ed. Rio de Janeiro: Civilização Brasileira, 1976.

ALVES, J. V. Portella F. Seis séculos de Artilharia: a História das armas dos fogos, largos, poderosos e profundos. V. 256 e 257, Rio de Janeiro: Biblioteca do Exército Editora, 1959.

ANDRADE, Celeste Maria Pacheco de. Origens do povoamento de Feira de Santana: um estudo de História colonial. Dissertação. Faculdade de Filosofia, Salvador: UFBA, 1990. Disponível em: <http://www.ppgh.ufba.br/wp-content/uploads/2015/03/Origensdo-Povoamento-PDF-A.pdf>. Acesso em: 18/03/17.

AQUINO, Rubem Santos Leão. História das Sociedades: das comunidades primitivas às sociedades Medievais. 10a ed. Rio de Janeiro: Ao Livro Técnico, 1980.

BOAVENTURA, Eurico Alves. Fidalgos e V aqueiros. Salvador: Centro Editorial e Didático da UFBA, 1989.

CASSIMIRO, Ana Palmira Bittencurt Santos. Cartilhas e catecismos usados no Brasil Colonial. Revista Educaşão em Questão, Natal, n. 22, 8, 182-205, 2005. Disponível em: http://www.revistaeduquestao.educ.ufrn.br/pdfs/v22n08.pdf $>$. Acesso em: 18/03/17.

CHAUÍ, Marilena. Convite à Filosofia. São Paulo: Ática, 2010.

GALVÃO, Mons. Renato de Andrade. Os povoadores da região de Feira de Santana. Sitientibus, Feira de Santana, n. 1, 1, 25-31, 1982. Disponível em:

<http://www2.uefs.br/sitientibus/pdf/1/povoadores_da_regiao.pdf $>$ Acesso em 18/03/17.

GRANDE ENCICLOPÉDIA LAROUSSE CULTURAL. São Paulo: Nova Cultural Ltda, 1995-1998.

MAGALHÃES, Couto de. O Selvagem. Rio de Janeiro: Typographia da Reforma, 1876. Disponível em: <http://www2.senado.leg.br/bdsf/handle/id/182909>. Acesso em: 18/03/17.

MATTOS, Luis Alves de. Primórdios da Educação no Brasil, o período heróico (1549 a 1570). Rio de Janeiro: Gráfica Aurora Ltda, 1958.

MORAIS, Jaime Magalhães. Origens do Tabaréu. [on-line], Webartigos, 2012. Disponível em:

<http://www.webartigos.com/_resources/files/_modules/article/article_99367_20121 119144720a6a1.pdf>. Acesso em: 18/03/17.

NETO, Ricardo Bonalume. Chuva de Aço, Abril Coleções (organizador); tradução de Mariane Janikian. São Paulo: Revista Abril Coleções, Artilharia 1850-1945, pp. 6-23, 2010. 
PITA, Sebastião da Rocha. História da América portuguesa. Lisboa: Editora LISBOA OCCIDENTAL, 1730.. Disponível em:

<http://www.brasiliana.usp.br/bbd/handle/1918/01495300\#page/21/mode/1up>. Acesso em: 18/03/17.

RENAULT, Victor. Thesouro das Famílias: ou dos conhecimentos úteis, enciclopédia da Vida prática. Rio de Janeiro: Editora H. Garnier, 1910.

SAMPAIO, Teodoro. O tupi na geografia. Salvador: Revista do IGHB, 1958.

SOUZA, Gabriel Soares de. Tratado descritivo do Brasil em 1587. Rio de Janeiro: Tipografia Régia, 1851. Disponível em:

< http://www.dominiopublico.gov.br/download/texto/me003015.pdf>. Acesso em 18/03/17.

TAVARES, Luis Henrique Dias. História da Babia. $10^{a}$ ed, Salvador: Editora EDUFBA, 2001. 